\title{
Internet of Things: A Review on Technologies, Architecture, Challenges, Applications, Future Trends
}

\author{
Jaideep Kaur \\ Guru Nanak Dev University/Department of CET, Amritsar, 143005, India \\ E-mail: jaideepmudhar@gmail.com \\ Kamaljit Kaur \\ Guru Nanak Dev University/Department of CET, Amritsar, 143005, India \\ E-mail: kamal.aujla86@gmail.com
}

\begin{abstract}
World Wide Web (1990's) and Mobile Internet (the 2000's) had consequential corroborated the way how people communicate. However, with evolution in technology, the cataclysm of Internet has stepped into a new phase-Internet of Things. Internet of Things, a prominent paradigm in the field of IT having a nominal intervention of humans allowing diverse things to communicate with each other, anticipate, sight, and perceive surroundings. IoT exploits RFID tags, NFC, sensors, smart bands, and wired or wireless communication technologies to build smart surroundings, smart Homes, quick-witted intelligence in medical care, ease of Transport, and more. This paper introduces IoT with emphasis on its driver technologies and system architecture. In addition to application layer protocols, we focus on identifying various issues and application areas of IoT as well as future research trends in the field of IoT. We have also highlighted how big data is associated with Internet of Things.
\end{abstract}

Index Terms-Applications, Architecture, Big Data, Economics, Internet of Things (IoT), Protocols.

\section{INTRODUCTION}

World Wide Web (1990's) and Mobile Internet (the 2000's) had consequential corroborated the way how people communicate. However, with an evolution in technology, the cataclysm of Internet has stepped into a new phase 'Internet of Things-The next generation technology'.

Internet of things (IoT) provides a communication platform supporting person to person (P2P), Machine to Machine (M2M) and Person to Machine (P2M) interactions. Thus, IoT reckons to 'Accumulate and Ubiquitous'. Fig. 1 shows Accumulate and Ubiquitous IOT.

Internet of Things- A prominent paradigm in the field of IT has a nominal intervention of humans, it is a network where miscellaneous things like animals, plants, vehicles, appliances, buildings dialogue information via the internet. IoT makes our surroundings smart by exploiting RFID tags, sensors, mobile phones, spime, Internet protocols, and wired or wireless communication technologies. The authors in [8] deployed Bluetooth Low Energy (BLE) technology for energy efficient smart homes. Tabish et al. [54] used 6LoWPAN to remotely monitor patient's health.

IoT has been included in first six 'Disruptive Civil technologies' list by US National Intelligence Council(NIC) [85]. NIC also envisions IoT to be present in everything be it furniture, paper, food packages or anything by 2025 . By 2020, CISCO gauge to approximately 50 billion IoT objects. In 1999, Kevin Ashton first coined the term 'Internet of Things'.

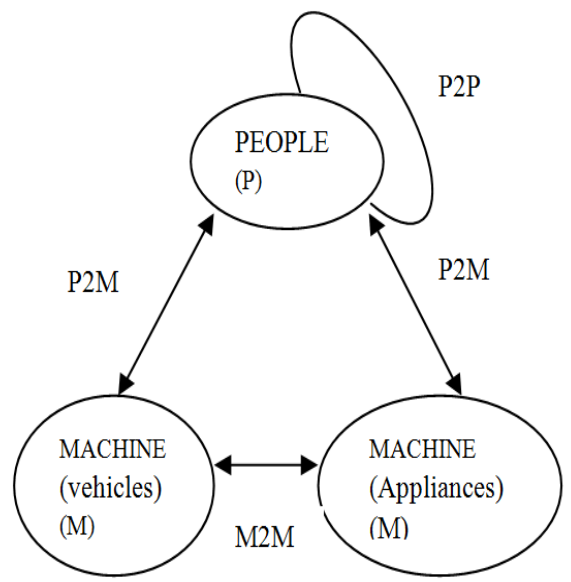

Fig.1.Accumulate and Ubiquitous IOT

Gubbi et al. define IoT as:

"Interconnection of sensing and actuating devices providing the ability to share information across platforms through a unified framework, developing a common operating picture for enabling innovative applications. This is achieved by seamless ubiquitous sensing, data analytics and information representation with Cloud computing as the unifying framework [3]." 
IoT sensors enable things (real/physical) to anticipate, sight, perceive and conduct jobs as living things do. For example, a wristband with embedded sensors monitor your sleeping and waking time and set an alarm accordingly, this wristband can then convey a message to the bath tub to start warming water and can even communicate to the coffee maker to prepare coffee. Thus, IoT cannot only sense things but it can also control and actuate things.

Things can be uniquely identified by assigning Identification through IPv6 addressing. Current IPv4 have the capability to address only 4.3 billion devices whereas IPv6 has an address space ranging from 2 to $128^{\text {th }}$ power devices that count to trillions of devices. With Unique identification, things can be easily located, recognized and controlled via the internet. IoT is considered essential in performing everyday activities. It can connect, Monitor heterogeneous things around us, locate things present around the globe, automatically manage and control things.

Deploying IoT in our daily activities can the increase quality of life and can even help in the growth of the economy. By 2025, approximately 2-3 billion people will access the internet also economic growth caused by IoT is estimated to be in the range of $\$ 2.7$ trillion to $\$ 6.2$ trillion [55]. Table 1 shows various application areas and the percentage they have an impact on economic growth. From this Medical Care is found to benefit economic growth at the most followed by Manufacturing then Electricity.

Table 1. Percent of Economic Growth Caused By Deploying Iot in Various Application Arenas

\begin{tabular}{|c|c|}
\hline APPLICATION ARENAS & PERCENTAGE \\
\hline Medical Care & $41 \%$ \\
\hline Manufacturing & $33 \%$ \\
\hline Electricity & $7 \%$ \\
\hline Metropolitan Infrastructure & $4 \%$ \\
\hline Safety & $4 \%$ \\
\hline Resource Extortion & $4 \%$ \\
\hline Agriculture & $4 \%$ \\
\hline Vehicles & $2 \%$ \\
\hline Retail & $1 \%$ \\
\hline
\end{tabular}

With IoT, many multinational software companies have switched to the physical world. For instance, Google collaborated with a thermostat company to create its mark in providing smart world/homes. IBM also leveraged IoT for traffic management and provides solutions for smart Grids. Various other companies such as Facebook, Apple envision IoT as its future technology.

IoT has a high significance in our day to day life. It has its vision in business, working and domestic domains such as assisted living, e-healthcare, industrial manufacturing, automation, management, smart transportation and abundant. In [8] [28] IoT is deployed for energy efficient smart Homes and Appliances, [33] deploys Arduino to monitor Air quality. Industry manufacturing processes are made efficient and more economic decisions are made with IoT [36] [27]. In [39] an author proposed an approach to control traffic congestions as well as provides smart car parking. IoT has its application in making green, safe and secure cities [31] [34].

Section II describes various components required for the functioning of IoT devices and various IoT technologies. These technologies include RFID which is the first hardware embedded in IoT devices, its main functionality is automatic identification, authentication, and tracking; Near Fields communication (NFC) - A wireless communication technology is capable of sharing data within the range of $10 \mathrm{~cm}$; ZigBee is another communication technology based on IEEE 802.15.4; 6LowPAN - An IoT communication technology that adequate IPv6 packets to IEEE 802.15.4 specification and provides multi-hop delivery. This section further reviews the applications where these technologies have been utilized. Section III highlights IoT's system Architecture. Section IV describes various application layer protocols and their comparison. Section $\mathrm{V}$ reviews proposals devised for various IoT complications such as energy efficiency, cost efficiency, availability, security, scalability, reliability. Section VI addresses application areas leveraged by IoT. Section VII highlights future research trends. Section VIII associates Big Data with IoT and Section IX concludes the paper.

\section{COMPONENT PREREQUISITE FOR INTERNET OF THINGS}

This section describes various components required for the functioning of IoT devices and various IoT technologies. These technologies include RFID which is the first hardware embedded in IoT devices, its main functionality is automatic identification, authentication, and tracking; Near Fields communication (NFC) - A wireless communication technology is capable of sharing data within the range of $10 \mathrm{~cm}$; ZigBee is another communication technology based on IEEE 802.15.4; 6LowPAN - An IoT communication technology that adequate IPv6 packets to IEEE 802.15.4 specification and provides multi-hop delivery. IoT exploits RFID tags, NFC, sensors, smart bands, and wired or wireless communication technologies to build smart surroundings, smart Homes, quick-witted intelligence in medical care, ease of Transport, and more.

There are three components that are required for proper functioning of IoT. These are:

1) Hardware and technologies - It incorporates sensors, actuators and other embedded devices and technologies.

2) Middleware - It comprises of repository and data analytic tools.

3) Display - It comprises of some presentation tools required for user interaction.

Fig. 2 shows various components that sum to IoT. 


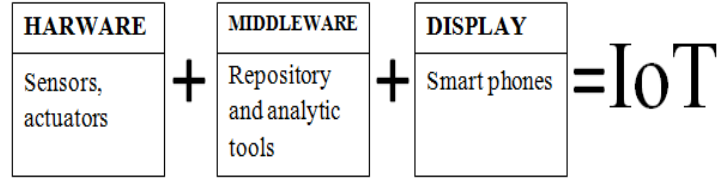

Fig.2. Various Components of IoT

This section expounds IoT components as follows:

\section{A. Hardware}

Hardware associated with IoT collects required data from the surroundings. IPv6, RFIDs, NFC, BLE, ZigBee, 6LowPan, WiFi, LTE (Long Term Evolution) are some enabling technologies that gather IoT data.

\section{Radio Frequency Identification (RFID)}

RFID is first technology that exists from the time when the concept of IoT was found in late 90's. RFID is a hardware embedded in the device; its main functionality is automatic identification, authentication, and tracking. RFID consists of passive RFID tags and active RFID readers. Passive RFID tags do not operate on batteries and it conveys ID to the active RFID readers. Active RFIDs are associated with the battery and it initiates communication. Healthcare, supply chain management, automatic recycling are some applications of RFIDs.

\section{Near Field Communication (NFC)}

Near Fields communication (NFC) is a wireless communication technology that has the capability of sharing data among electronic devices within the range of $10 \mathrm{~cm}$. NFC works at a high frequency of $13.56 \mathrm{MHz}$ and up to $424 \mathrm{Kbps}$ of the data rate. Smart transportation, IPv6 packet transmission are some application areas where NFC technology is leveraged.

\section{ZigBee}

ZigBee is another communication technology based on IEEE 802.15.4. It was standardized in 2003 later was revised in 2006. ZigBee provides high-level communication among IoT devices with coverage of 10$100 \mathrm{~m}$. It also has its proficiency in monitoring, authentication but does not guarantee QoS. It is a costeffective technology and consumes less energy, so it can be deployed in electric meters, wireless light switches, industrial tools that require short-range data transfer. Applications include Smart Homes, Super Market and more.

\section{Bluetooth low energy (BLE)}

Bluetooth low energy (BLE) as the name suggests is a wireless technology that is proficient in reducing power consumptions, thus increasing the lifespan of devices. BLE uses shorter wavelength, operates in the range of $100 \mathrm{~m}$ but have 15 times lower latency than traditional Bluetooth. It follows a master-slave approach. Almost all Smartphones are leveraging this technology to a greater extent. BLE is coherent in consuming energy as compared to ZigBee. Applications include Data transmission, Home appliances, Vehicle to Vehicle communication and more.

\section{LowPan}

IPv6 over low-power wireless personal area network (WPANs) abbreviated as 6LowPAN is an IoT communication technology that adequate IPv6 packets to IEEE 802.15.4 specification. In 2007, IETF 6LowPAN working group follow this standard.

6LowPAN foreshortens transmission overhead by performing comparisons. It also supports multi-hop delivery [86] and is capable of providing security and protection in IoT environment. It operates in the range of 10-30 m. The datagram of 6LowPAN incorporates 4 types of 2 bit headers. 00 represents 'No Header' and jettison all those packets that discard to 6LowPAN. 01 typify to 'Transmit Header'. This Header accomplishes multi-casting and constricts IPv6 header. 10 represent 'Reticulation addressing'. It is capable of identifying IEEE 802.15.4 packets. 11 represent fragmentation. Applications include Intrusion detection system, Healthcare.

Table 2 illustrates Attributes of Technologies used in Internet of Things.

Table 2. Attributes of Technologies used in Internet of Things

\begin{tabular}{|c|c|c|c|c|}
\hline Technology & Proficiency & $\begin{array}{l}\text { Data } \\
\text { Rate }\end{array}$ & Range & Applications \\
\hline RFID & $\begin{array}{l}\text { Authentication } \\
\text { Monitoring, } \\
\text { Identification, } \\
\text { Information } \\
\text { Management }\end{array}$ & $\begin{array}{l}\text { Up } \\
\text { to } \\
640 \\
\text { kbps }\end{array}$ & $1-10 \mathrm{~m}$ & $\begin{array}{l}\text { HealthCare[17], } \\
\text { Supply chain } \\
\text { Management } \\
\text { [56], } \\
\text { Automotive } \\
\text { Recycling } \\
\text { Industry[57], } \\
\text { Object } \\
\text { Tracking[58], } \\
\text { warehouse } \\
\text { management[59] }\end{array}$ \\
\hline $\mathrm{NFC}$ & $\begin{array}{l}\text { communicatio } \\
\mathrm{n}, \\
\quad \text { Security }\end{array}$ & $\begin{array}{l}106- \\
424 \\
\text { kbps }\end{array}$ & $\begin{array}{l}\leq 10 \\
\mathrm{~cm}\end{array}$ & $\begin{array}{l}\text { Smart } \\
\text { Transportation } \\
\text { [60], } \\
\text { Electronic } \\
\text { Lock[61],IPv6 } \\
\text { packet } \\
\text { transmission[62] }\end{array}$ \\
\hline 6LowPan & $\begin{array}{l}\text { Protection and } \\
\text { Security }\end{array}$ & $\begin{array}{l}20- \\
250 \\
\text { kbps }\end{array}$ & $\begin{array}{l}10-30 \\
\mathrm{~m}\end{array}$ & $\begin{array}{l}\text { Intrusion } \\
\text { Detection } \\
\text { System [63], } \\
\text { HealthCare[64] }\end{array}$ \\
\hline BLE & $\begin{array}{l}\text { communicatio } \\
\mathrm{n} \text {, } \\
\text { Reduce power } \\
\text { consumption }\end{array}$ & $\begin{array}{l}1 \\
\mathrm{mbp} \\
\mathrm{s}\end{array}$ & $100 \mathrm{~m}$ & $\begin{array}{l}\text { Data } \\
\text { transmission } \\
{[65],} \\
\text { Home appliances } \\
{[66],} \\
\text { Smart Home[8] }\end{array}$ \\
\hline ZigBee & $\begin{array}{l}\text { communicatio } \\
\mathrm{n} \text {, } \\
\text { monitoring }\end{array}$ & $\begin{array}{l}20- \\
250 \\
\text { kbps }\end{array}$ & $\begin{array}{l}10- \\
100 \mathrm{~m}\end{array}$ & $\begin{array}{l}\text { Smart } \\
\text { Home[67], } \\
\text { Super } \\
\text { Market[68] }\end{array}$ \\
\hline
\end{tabular}

\section{B. Middleware}

In order to aid repository and data analytics, a centralized system is a must. IoT paradigm results into the creation of abundant data. This data must be stored 
efficiently and intelligently in order to perform actuation and smart observations. A centralized system provides reliability. The data so generated by IoT can be stored in a cloud-based repository.

\section{Display}

Display components of IoT consist of those tools that provide user interaction with the scenario. Since most users of IoT are non-technical, it becomes a necessity to develop devices that are easy to operate and from which user can have maximum benefit from. Devices such as smart phones, smart tablets, 3D screen etc. fall under this category.

\section{IOT SYSTEM ARCHITECTURE}

IoT system architecture has the ability to perform interoperability among heterogeneous assets around us. Considering the aforementioned fact, the architecture of IoT should be flexible layered [1]. As there is no commonly accepted IoT architecture, authors proposed various architectures, few among them are SoA based architecture proposed by Atzori et al. [2] and five-layered architecture [86].

\begin{tabular}{|c|}
\hline Applications \\
\hline $\begin{array}{c}\text { Service } \\
\text { Composition }\end{array}$ \\
\hline $\begin{array}{c}\text { Service } \\
\text { Management }\end{array}$ \\
\hline Object Abstraction \\
\hline Objects \\
\hline
\end{tabular}

(a)

\begin{tabular}{|c|}
\hline BUSINESS LAYER \\
\hline APPLICATION LAYER \\
COAP, MQTT, XMPP, DDS, AMQP \\
\hline SERVICE MANAGEMENT LAYER \\
\hline OBJECT ABSTRACTION LAYER \\
\hline OBJECTS/PERCEPTION LAYER \\
\hline
\end{tabular}

(b)

Fig.3. (a) SoA (Service Oriented Architecture) [2] (b) Five Layered Architecture.
A brief introduction to the five layers of IoT system architecture is as follows:

\section{A. Objects or assets layer (Perception layer)}

The lowest layer of IoT architecture is responsible for gathering data from the surroundings wielding sensors and actuators. It is proficient in identifying location, monitoring room temperature and humidity, recording vehicle acceleration and more. It digitizes the sensed data and communicates to the object abstraction layer.

\section{B. Objects Abstraction layer}

Through various communication technologies counterpart RFID, ZigBee, 6LowPAN, WiFi, 3G/4G, BLE etc. this layer act as a bridge to transfer incoming digitized data from objects layer to the service management layer. This layer is also responsible for cloud computing functionalities [87].

\section{Service Management layer}

It is a middleware layer that after identifying the names and address provides service to its requestors. It is the layer with the help of which IoT is capable of connecting with heterogeneous things.

\section{Application layer}

The Application layer is associated with delivering services to the customers. For instance, it can give the acceleration of the vehicle as well as an exact location of the vehicle. Various application domains include Smart Home, Smart Grid, Intelligent Transport, Smart Factory, Quick-witted HealthCare intelligence and more. Application layer incorporates CoAP (Constrained Application Protocol), AMQP (Advanced Message Queuing Protocol), DDS (Data Distribution Service), MQTT (Message Queue Telemetry Transport), XMPP (Extensible Messaging and Presence Protocol) protocols. These protocols are discussed in next section.

\section{E. Business layer}

The Business layer also named as management layer manages all layers, activities, and service of IoT. It incorporates certain graphs, flowcharts, and models based on the data acquired from the application layer. This layer is capable of making effective decisions for big data analysis.

\section{PROTOCOLS ASSOCIATED WITH APPLICATION LAYER OF IOT}

The Application layer of IoT system architecture furnishes user services by following certain rules and procedures called Application layer protocols. These protocols include:

CoAP (Constrained Application Protocol).

MQTT (Message Queue Telemetry Transport).

XMPP (Extensible Messaging and Presence Protocol).

AMQP (Advanced Message Queuing Protocol).

DDS (Data Distribution Service). 
Among these CoAP and MQTT are most disseminate protocols. A detailed description of these protocols is discussed as follows:

\section{A. Constrained Application Protocols (CoAP)}

CoAP is a retransmission protocol that features request and response messaging. It was standardized by Internet Engineering Task Force (IETF) constrained Restful environment. CoAP was basically designed for resource constrained devices like WSN (Wireless Sensor Networks). The main functionality of CoAP is monitoring, controlling remote devices as well as guarantying message delivery. CoAP leverages HTTP commands GET, POST, PUT and DELETE for interactions between client and server. It relies on UPD (User Datagram Protocol).

CoAP is divided into two sub-layers namely message sub-layer and request/response sub-layer. The former ensures reliable communication based on exponential back off and later deals with REST communications.

CoAP is proficient in providing Datagram transport layer security (DTLS) that provides privileged message communication, minimizing communication overhead and monitoring resources by utilizing publish/subscribe mechanism. Confirmable, Non-Confirmable, Acknowledgment (Piggybacked) and Separate Response are four types of CoAP messages. CoAP has a 32 bit message format. Fig. 4 shows CoAP message format. It incorporates CoAP version $(\mathrm{V})$, Transaction Type $(\mathrm{T})$, OC (Option Count), Code and Message ID (M ID) in header field followed by Token, Options and Payload fields.

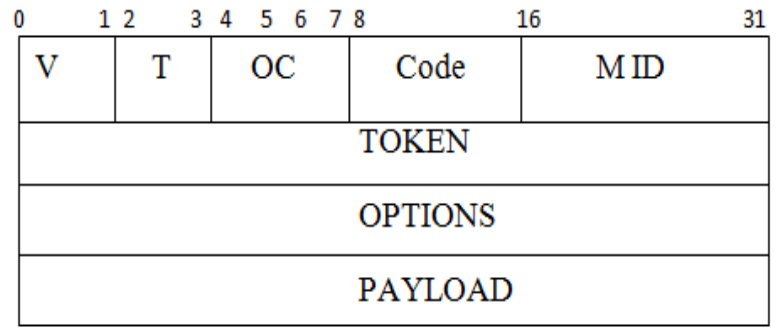

Fig.4. CoAP Message Format

Various Application domains where CoAP is utilized are personal HealthCare Systems [9], Resource Sharing [10], Congestion Control [13], and Security [37].

\section{B. Message Queue Telemetry Transport(MQTT)}

MQTT is a lightweight messaging protocol that supports machine to machine communication. It relies on TCP. In comparison to CoAP, MQTT has higher throughput but lower Latency [88]. It was developed by IBM in collaboration with Arcom in 1999 and later was standardized as OASIS in March 2013.

MQTT utilizes Publish/Subscribe messaging mechanism and provides SSL (Service Socket Layer) encrypted link between client and Broker.

It has 3 QoS levels:
1) Fire and Forget - Fire the message and Forget i.e. no acknowledgment is received.

2) Delivered at least once - Message is delivered at least once and for each delivery acknowledgment is received.

3) Delivered exactly once - In order to guarantee message delivery, 4-way handshake procedure opts.

The Client-Server of MQTT comprises of 3 elements:

1) Subscriber.

2) Publisher.

3) Broker.

Every server in this architecture is referred to as broker. Client subscribes to a topic generated by the publisher. The Publisher on the other hand forwards the generated topic to the broker. For Instance, Consider three clients A, $\mathrm{B}$, and $\mathrm{C}$. Here Client $\mathrm{A}$ is a Publisher that publishes a topic 'air humidity' and Client $\mathrm{B}$ and $\mathrm{C}$ subscribes to this topic. Now, whenever Client A publishes the value of air humidity says 49 then the intermediate broker gives access of this value to all the subscribed Clients.

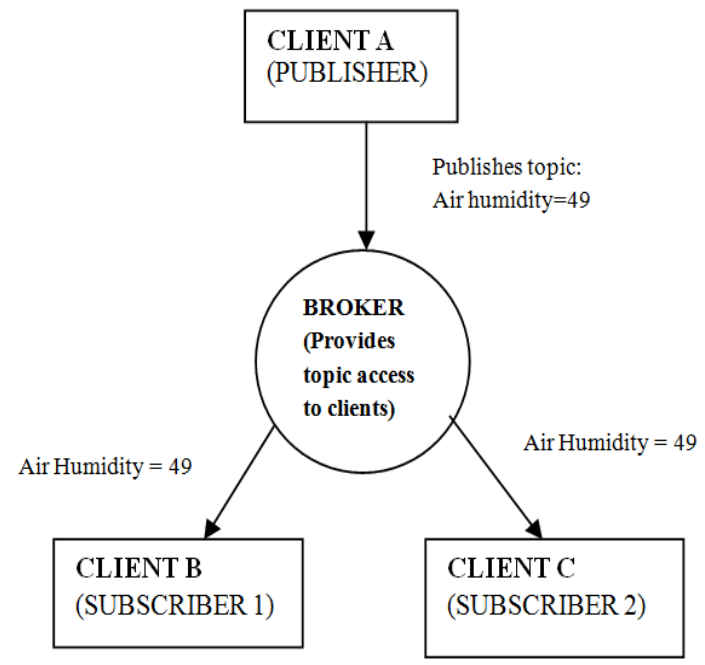

Fig.5. Publisher/ Subscriber MQTT Architecture

The message format of MQTT consists of four bytes header, 1-4 bytes length, variable length header and variable length message payload. Fig. 6 shows MQTT message format.

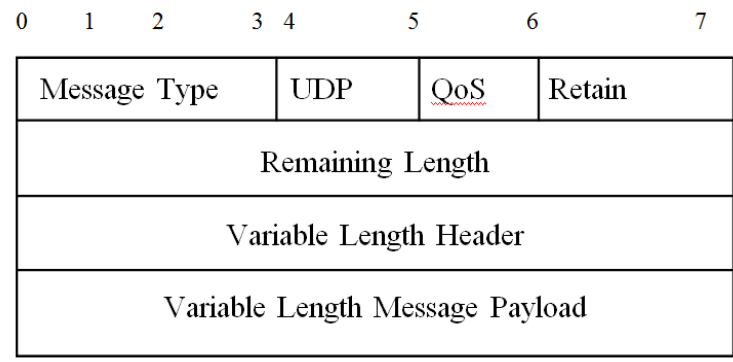

Fig.6. MQTT Message Format 
Applications include medical information sharing [21], power meters, observations and more.

\section{Extensible Messaging and Presence Protocol (XMPP)}

XMPP is an XML, TCP based Messaging protocol that was invented by Jaber open Source community to ensure SSL confidential message communication. It became an IETF instant messaging standard in 2002.

XMPP has its applications in social networking such as multi-user chat, video/voice calling and more. It is a platform independent protocol, have no QoS support and supports Publish/Subscribe and Request/ Response.

Two or more users exchange data in the form of XML Stanza. XML stanza is cleaved into 3 components.

1) Message - it identifies source and destination address, type and IDs.

2) Presence - it notifies updates to the customers.

3) Info/query - It pairs sender and receiver.

Shows XML Stanza of XMPP [1].

\begin{tabular}{|c|}
\hline <stream> \\
\hline $\begin{array}{c}\begin{array}{c}\text { presence> } \\
<\text { show } />\end{array} \\
<\text { presence> }\end{array}$ \\
\hline $\begin{array}{c}\langle\text { message to }=\text { 'x }> \\
<\text { body }> \\
</ \text { message }>\end{array}$ \\
\hline $\begin{array}{l}\begin{array}{c}<\text { iq to }=\text { 'y'y } \\
\quad<q u e r y /> \\
</ \text { iq }>\end{array}\end{array}$ \\
\hline$</$ stream $>$ \\
\hline
\end{tabular}

Fig.7. XML Stanza of XMPP [1]

\section{Advanced Message Queuing Protocol (AMQP)}

AMQP is an open standard application layer protocol that provides reliable communication over TCP transmission. It is proficient in providing security, routing

AMQP ensures reliable message delivery through at most once, at least once, and exactly once delivery. It supports Publish/Subscribe messaging procedure. The message format of AMQPP consists of 8 bytes header. Fig. 8 represents AMQP message format.

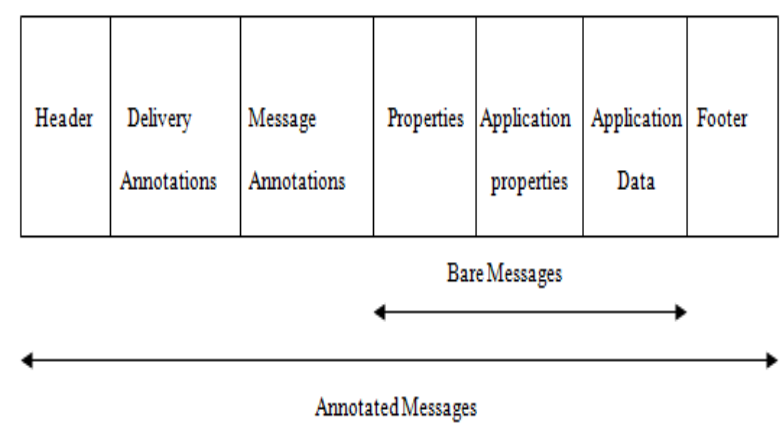

Fig.8. AMQP Message Format [1]

\section{E. Data Distributed Service (DDS)}

DDS was designed for real time Machine to machine interactions by Object Management Group (OMG). It is a broker-less Publish/Subscribe architecture in comparison to MQTT, AMQP, and XMPP. DDS is highly reliable which provides both SSL and DTLS secure message communication. It supports both TCP and UDP transmission and has 23 QoS policies namely Security, durability, priority, reliability, etc.

Table 3 demonstrates the comparison between application layer protocols of IoT.

Table 3. Comparison of Application layer protocols of IoT

\begin{tabular}{|c|c|c|c|c|c|}
\hline$\underbrace{\text { Protocol }}_{\text {Parameter }}$ & CoAP & MQTT & XMPP & AMQP & DDS \\
\hline Security & DTLS & SSL & SSL & SSL & $\begin{array}{l}\text { SSL, } \\
\text { DTLS }\end{array}$ \\
\hline Messaging & Request/Response & $\begin{array}{l}\text { Publish/ } \\
\text { Subscribe }\end{array}$ & $\begin{array}{l}\text { Request/Response } \\
\text { Publish/ } \\
\text { Subscribe }\end{array}$ & $\begin{array}{l}\text { Publish/ } \\
\text { Subscribe }\end{array}$ & $\begin{array}{l}\text { Broker-less } \\
\text { Publish/ } \\
\text { subscribe }\end{array}$ \\
\hline Transport & UDP & TCP & TCP & TCP & TCP,UDP \\
\hline QoS & $\begin{array}{l}\text { Confirmable: } \\
\text { Acknowledgment } \\
\text { Non- confirmable: } \\
\text { fire and forget }\end{array}$ & $\begin{array}{l}\text { Levels: } \\
\text { Fire forget } \\
\text { delivered at least } \\
\text { once delivered } \\
\text { exactly once }\end{array}$ & $\begin{array}{l}\text { No support for } \\
\text { QoS }\end{array}$ & $\begin{array}{l}\text { support for } \\
\text { QoS }\end{array}$ & $\begin{array}{l}23 \text { policies: } \\
\text { Security, } \\
\text { reliability, } \\
\text { durability, } \\
\text { priority etc. }\end{array}$ \\
\hline $\begin{array}{l}\text { Header Size } \\
\text { Of Message } \\
\text { Format } \\
\end{array}$ & 4 & 2 & $\begin{array}{l}\text { no Header } \\
\text { Uses XML Stanza }\end{array}$ & 8 & - \\
\hline Dependability & Non-dependable & Dependable & Dependable & Dependable & $\begin{array}{l}\text { Highly } \\
\text { dependable }\end{array}$ \\
\hline
\end{tabular}

\section{PROPOSALS DEVISED FOR VARIOUS COMPLICATIONS ENCOUNTERED IN IOT}

IoT networks should be such that they are able to withstand any failure or damage caused to them. Thus, a durable IoT network is a great challenge for IoT. Anywhere and anytime availability of data is of great concern, this challenge can be resolved if both hardware and software availability is realized. With an Introduction 
to IoT, a number of devices have been automated and it consumes electricity. But for efficient energy consumption green IoT is a must. This section reviews proposals devised for various IoT complications such as energy efficiency, cost efficiency, availability, security, scalability, reliability.

\section{A. Propensity in Reciprocity of Data}

Since Internet of things revolves around miscellaneous things having divergent platforms around us, these things must perform node to node interoperability for proper functioning. Hence, Propensity in the reciprocity of data becomes an IoT challenge. It is a challenge both for manufacturers and developers to deliver services irrespective of the platform user's are operating on. It is also a duty for developers to develop applications in which addition of new functions do not disturb the interaction that an application is having with other application. Through NFC, WiFi and GSM Smart Phones perform interoperability. Kiljander et al. [42] proposed Interoperability architecture for Internet of Things. This architecture postulates that universal IoT is cleaved into smaller smart areas and these smart areas exchange information by Semantic Information Broker (SIB). SIB supervises and reforms real time events with SPARQL. On Evaluation, the proposed architecture affirmed to IoTA ARM (Architecture Reference Model).

\section{B. Sturdy in Establishment of Networks}

IoT networks should be such that they are able to withstand any failure or damage caused to them. Thus, a durable IoT network is a great challenge for IoT. Heterogeneous IoT networks may encounter node failures due to low energy, hardware impairments, software error or spiteful attacks. Multimedia devices encounter such failures. Qiu et al. [6] proposed a Greedy Model that encompasses small world properties. Qui et al. Compared GMSW (Greedy Model with Small World) with DASM (Directed Angulations toward the Sink Node Model) in terms of robustness and examined that the proposed model had lower latency than DASM. To forge a resilient approach for multimedia transference on changing topologies, Rosario et al. [30] introduced a protocol named LinGO (Link quality and Geographical beaconless OR). LinGO on evaluation endows increase in packet delivery rate, QoS.

\section{Anywhere and at anytime Availability of Data}

Anywhere and anytime availability of data is of great concern, this challenge can be resolved if both hardware and software availability is realized. Software availability deals with providing application services to all users at any time and at any place. On the other hand, hardware availability refers to the anytime and anywhere availability of IoT compatible devices.

These days' smartphones are deemed to accumulate data; they are capable of storing piles of information. With this context, Santos et al. [9] proposed a system based on CoAP to accumulate data of medical care devices so that this data is available over the internet as well as a on home network. CoAP on comparison with other IoT application layer protocols was found to be $50 \%$ lighter. Vargheese et al. [53] collected data from sensors deployed in hospital in order to provide better medical services to the patients. The authors proposed e-health architecture to ensure availability of patient's data whenever needed. Fang et al. [52] presented IIS that integrated IoT, Cloud Computing, GIS, and GPS. IIS leveraged IoT for collecting sensor data.

\section{Regulates Escalation in Energy Efficiency}

In [8] Collotta and Pau addressed a fuzzy logic approach in order to forge energy efficient smart homes. BLE supported home devices were monitored against battery consumptions and Throughput/workload ratio. It was analyzed that life expectancy of devices increases by $30 \%$.

With an Introduction to IoT, a number of devices have been automated and it consumes electricity. But for efficient energy consumption green IoT is a must. To resolve this problem Huang et al [38] proposed a Steiner tree algorithm to have devices that consume less energy and have a longer lifespan. On evaluation, it was observed that the proposed algorithm was more energy efficient compared to WSN. Kim et al. [28] presented a scheme named 'DAOT- Dynamic and energy-aware Authentication scheme for Internet of Things'. DAOT prevents IoT devices from MITM security attacks by leveraging energy aware security strategy. DAOT is cost and energy efficient. In [20], authors analyzed one-year energy utilization of a building. They envisioned that existing green IoT structure may not be efficient. To resolve this problem, authors' leveraged smartphones and cloud computing was leveraged to propose an IoT framework. This framework helped in the growth of the economy, reduction in energy consumption and better civilization.

\section{E. Cost efficiency in terms of providing services}

With an advent of IoT, Hussain et al. [29] proposed an IoT-based framework to monitor medical status of aged and handicapped people. This framework recommended service offerings in emergency situations. On executing, the proposed framework was observed to be cost effective and productive.

Abraham and $\mathrm{Li}$ [34] presented a cost-effective air pollution monitoring system. This system is embedded with Arduino, inexpensive micro gas sensors and ZigBee networks. It is effective in producing a healthy environment.

\section{F. Degree of Sanctuary}

It is a difficult task to ensure security in heterogeneous IoT networks where billions and trillions of devices share data. In order to have secured link between these things Pereira et al. [45] proposed a CoAP dependent scheme. This scheme provides user authentication, it allows only authenticated users to access read/write commands. For instance, a user authenticated for the read operation cannot perform the modification. By implementing this 
scheme on client server machine, it was possible to identify a user's I/O request and send a response to the request.

For secure transmission of data over IoT, Mao et al. [11] compared existing and proposed FIBE models. On analysis, it was found that proposed FIBE was more secure in dissemination and had fewer parameters. Kantarci and Moftah [42] presented a cloud platform named TSCM to ensure mob protection in various events such as bidding. On Evaluating TSCM, it was observed that spiteful users impression lowered by $75 \%$ and reliability by $40 \%$ also TSCM can be leveraged to $85 \%$.

\section{G. Workload Conduct}

Jiang et al. [7] identified the challenge of handling Big Data gathered from sensors. An increase in demand for mining this data, Jiang et al. [7] presented a secure, reliable and scalable storage system. Due to a rapid increase in the number of mobile users, it has become an issue to share hardware and software resources needed by mobile apps. To resolve this issue Xue and Dateres [10] addresses a horizontal scalability approach that creates an environment for providing hardware and software resources. Villalba et al [15] presented a scalable platform to perform mining of IoT data.

\section{H. Scalability}

IoT scalability refers to adjoining new features and functionalities to the IoT application without causing any loss of user information or data while maintaining and enhancing QoS. Due to the variety of platforms and protocol availability, it becomes challenging to perform scalability. Xue and Detera [10] introduced the concept of horizontally scalable applications so that diverse mobile phones are clubbed together into a single compute environment. Villaba et al. [15] developed an open source scalable project namely 'ServIoTicy and iServe'.

\section{Reliability}

A system ensures an increase in reliability in terms of IoT service delivery by consistently performing following its specifications. It is equivalent to availability as it ensures service delivery and takes both hardware and software into consideration. Zheng et al. [40] proposed reliable clustering anomaly detection in Smart Parking.

Table 4. Parametric Analysis of Work Done in Resolving Challenges Encountered in Internet Of Things.

\begin{tabular}{|c|c|c|c|c|c|c|c|c|c|}
\hline \multicolumn{7}{|c|}{ PUBLICATIONS } & \multicolumn{7}{|c|}{ PARAMETERS } \\
\hline REFERENCE & YEAR & SC & R & S & C & EE & AV & RB & I \\
\hline Qiu et al. [6] & 2016 & & & & & & & X & \\
\hline Jiang et al. [7] & 2015 & X & X & X & & & & & \\
\hline $\begin{array}{c}\text { Collotta and } \\
\text { Pau [8] }\end{array}$ & 2015 & & & & X & X & & & \\
\hline $\begin{array}{c}\text { Santos et al. } \\
\text { [9] }\end{array}$ & 2015 & & & & & & X & & \\
\hline $\begin{array}{c}\text { Xue and } \\
\text { Detera [10] }\end{array}$ & 2015 & X & & & & & & & \\
\hline $\begin{array}{c}\text { Mao et al. } \\
\text { [11] }\end{array}$ & 2015 & & & X & & & & & \\
\hline $\begin{array}{c}\text { Marjanovic et } \\
\text { al. [12] }\end{array}$ & 2015 & & & & & X & & & \\
\hline
\end{tabular}

\begin{tabular}{|c|c|c|c|c|c|c|c|c|c|}
\hline $\begin{array}{c}\text { Batzler et al. } \\
{[13]}\end{array}$ & 2015 & & $\mathrm{X}$ & & & & & & \\
\hline $\begin{array}{l}\text { Mcerreale et } \\
\text { al. [14] }\end{array}$ & 2015 & & & & & $\mathrm{X}$ & $\mathrm{X}$ & & \\
\hline $\begin{array}{c}\text { Villalba et al. } \\
{[15]}\end{array}$ & 2015 & $\mathrm{X}$ & & & & & & & \\
\hline $\begin{array}{c}\text { Chai et al. } \\
{[16]}\end{array}$ & 2015 & & & $\mathrm{X}$ & & & & & \\
\hline $\begin{array}{c}\text { He and } \\
\text { Zeadally [17] }\end{array}$ & 2015 & & & $\mathrm{X}$ & & & & & \\
\hline $\begin{array}{c}\text { Kumar et al. } \\
{[18]}\end{array}$ & 2015 & & & & & & & & \\
\hline $\begin{array}{l}\text { Premnath and } \\
\text { Hass[19] }\end{array}$ & 2015 & & & $\mathrm{X}$ & & & & & \\
\hline Pan et al. [20] & 2015 & & & & & $\mathrm{X}$ & & & \\
\hline $\begin{array}{c}\text { Gomes et al. } \\
{[21]}\end{array}$ & 2015 & & & & & & & & \\
\hline $\begin{array}{c}\text { Collier et al. } \\
{[22]}\end{array}$ & 2015 & & & & & $\mathrm{X}$ & & & \\
\hline $\begin{array}{c}\text { Suresh et al. } \\
{[23]}\end{array}$ & 2015 & & & $\mathrm{X}$ & & & & & \\
\hline $\begin{array}{c}\text { Pham et al. } \\
\text { [24] }\end{array}$ & 2015 & & & & $\mathrm{X}$ & & & & \\
\hline $\begin{array}{c}\text { Kalmar et al. } \\
{[25]}\end{array}$ & 2015 & & & & $\mathrm{X}$ & & & & \\
\hline Zhu et al. [26] & 2015 & & & & & $\mathrm{X}$ & & & \\
\hline Zhu et al. [27] & 2015 & & $\mathrm{X}$ & & & $\mathrm{X}$ & & & \\
\hline $\begin{array}{c}\text { Kim et al. } \\
{[28]}\end{array}$ & 2015 & & & $\mathrm{X}$ & $\mathrm{X}$ & $\mathrm{X}$ & & & \\
\hline $\begin{array}{c}\text { Hussain et al. } \\
{[29]}\end{array}$ & 2015 & & & $\mathrm{X}$ & $\mathrm{X}$ & & & & \\
\hline Rosario [30] & 2014 & & $\mathrm{X}$ & & & & & $\mathrm{X}$ & \\
\hline $\begin{array}{c}\text { Castro et al. } \\
{[31]}\end{array}$ & 2014 & $\mathrm{X}$ & & & & & & & \\
\hline $\begin{array}{c}\text { Luvisi and } \\
\text { Lorenzini [32] }\end{array}$ & 2014 & & & $\mathrm{X}$ & & $\mathrm{X}$ & & & \\
\hline C.Bekara [33] & 2014 & & & $\mathrm{X}$ & & & & & \\
\hline $\begin{array}{c}\text { Abraham and } \\
\operatorname{Li}[34]\end{array}$ & 2014 & & & & $\mathrm{X}$ & & & & \\
\hline $\begin{array}{c}\text { Elmaghraby } \\
\text { and } \\
\text { Losavio[35] }\end{array}$ & 2014 & & & $\mathrm{X}$ & & & & & \\
\hline $\begin{array}{c}\text { Nitti et al. } \\
{[36]}\end{array}$ & 2014 & $\mathrm{X}$ & $\mathrm{X}$ & & & & & & \\
\hline $\begin{array}{c}\text { Raza et al. } \\
\text { [37] }\end{array}$ & 2014 & & & $\mathrm{X}$ & & & & & \\
\hline $\begin{array}{c}\text { Huang et al. } \\
{[38]}\end{array}$ & 2014 & & & & $\mathrm{X}$ & $\mathrm{X}$ & & & \\
\hline $\begin{array}{c}\text { Fuhong et al. } \\
\text { [39] }\end{array}$ & 2014 & & & & $\mathrm{X}$ & $\mathrm{X}$ & & & \\
\hline $\begin{array}{c}\text { Zheng et al. } \\
{[40]}\end{array}$ & 2014 & & $\mathrm{X}$ & & $\mathrm{X}$ & $\mathrm{X}$ & & & \\
\hline $\begin{array}{c}\text { Chen et al. } \\
\text { [41] }\end{array}$ & 2014 & & & $\mathrm{X}$ & & & & & \\
\hline $\begin{array}{l}\text { Kantarci and } \\
\text { Mouftah[42] }\end{array}$ & 2014 & & & $\mathrm{X}$ & & & & & \\
\hline $\begin{array}{c}\text { Kiljander et } \\
\text { al. [43] }\end{array}$ & 2014 & & & & & & & & $\mathrm{X}$ \\
\hline Liu et.al[44] & 2014 & & & & & $\mathrm{X}$ & & & \\
\hline $\begin{array}{c}\text { Periera et al. } \\
{[45]}\end{array}$ & 2014 & & & $\mathrm{X}$ & & & & & \\
\hline $\begin{array}{c}\text { Castellani et } \\
\text { al. [46] }\end{array}$ & 2013 & & $\mathrm{X}$ & & & & & & \\
\hline $\begin{array}{c}\text { Palattella et } \\
\text { al. [47] }\end{array}$ & 2013 & & & & & $\mathrm{X}$ & & & \\
\hline Sun et al. [48] & 2011 & & & $\mathrm{X}$ & & & & & \\
\hline
\end{tabular}

SC: Scalability; R: Reliability; S: Security; C: Cost; EE: Energy Efficiency; AV: Availability; RB: Robustness; I: Interoperability 


\section{DIVERSE ARENAS LEVERAGING INTERNET OF THINGS}

IoT has a potential to enhance our day to day activities with an introduction of automated applications. These applications can be found in various domains such as Industry, Home/Buildings, Healthcare, Agriculture, Education, Smart Grid and abundant. A review regarding various areas where IoT is leveraged is as follows:

\section{A. Ease of Transportation or Intelligent Transportation System}

Presently all cars, buses, trains are advancing in features due to the advent of IoT. These vehicles are now equipped with sensors and actuators. Besides sensors and actuators certain tags like RFID, NFC, QR codes, barcodes, and digital watermarking are also being implanted. Sensors, actuators, tags are embedded in roads, parking lots, railway lines as well for reducing road congestion, traffic management, road safety, spotting parking locations etc. With the help of RFIDs and NFC passengers and Driver can have proper navigation of their routes; also tourists can have information for nearby hotels, restaurants, tourist places and more. In [23], authors leveraged IoT in airport parking systems where passengers can monitor their parked cars through smartphones. Authors in [70] proposed a feasible machine to machine middleware named ICSI based on smart transportation.

In metropolitan cities, due to large population traffic jams are observed for long hours due to this traffic people get late for their work. Keeping this in mind, Rathore et al. [69] proposed a graph-based approach to collect traffic information as well as the location of individual devices. For this sensors are deployed on the road which collects individual vehicles data also in other words 'Big data'. This data is then transformed into a graph using Giraph tool to achieve efficiency. Authors proved the proposed system to be efficient and scalable by implementing it on Giraph and Spark- a better approach than Hadoop.

\section{B. Quick witted Intelligence in Providing Healthcare Advice to Patients}

Internet of Things has great significance in the medical field; it can assist patients, provide health care services over internet, infant recognition to avert any mismatch, giving correct prescriptions, etc. Wearable wristbands, sensors embedded in human bodies can monitor patient's health status, detect heart rate, stress, Blood pressure, Sugar level etc. RFID, MQTT, CoAP, 6LowPAN are some of the technologies of great significance in providing IOT medical services. It can also be utilized to monitor elderly and disabled people.

Istepanian et al. [71], presented an intelligent architecture $-\mathrm{m}-\mathrm{IoT}$. This architecture deploys 6LowPan IoT technology to assist patients by monitoring their body temperature. IoT has tremendous applications in the field of Medical Care from assistance, care to awareness. Das et al. [72] proposed a cloud-based approach to make people aware of the health uncertainty they are encountering due to gleaming of lights. Lui et al. [73] introduced an intelligent communication system 'eBPlatform' for the doctors and patients of china. Sensors are deployed at native place of non-infectious patients. The sensors are capable of recording blood pressure, blood sugar and ECG of patients and transferring the details to doctors via online mode. A similar approach was proposed by Al-Taee et al. [74] where patients can monitor their diabetes through smartphones.

\section{Smart homes or Buildings}

IoT has huge potential for quality living and comfort. It can dim/brighten lights as time change; it can increase/ decrease room temperature. BLE, a low-cost technology is deployed for power efficient homes. For better sustainability and healthy environment IoT can be deployed for monitoring room air quality, open garage doors, automate all home appliances, thus acting as assistance in our busy schedules.

Choubey et al. [75] proposed a decision-making scheme to monitor devices installed at home collects sensory data, transmits it to Cloud Server and then takes the decision to minimize the use of the device that consumes high power/ electricity. In [76] Coelho et al. proposed a system to provide care for people. This system tracks the behavior of people and communicates any threat encountered to caretaking staff. Authors in [77] leveraged IoT technologies to provide secure, theft free smart homes or buildings.

\section{Exploiting Smart Industrial and Manufacturing Processes}

Advancement in Industry is not only beneficial to industrialists but it also leads to growth in country's economy. IoT provides efficient and smart solutions for automation of Industry and various manufacturing processes like car/aircraft manufacturing, printing and packing [78], performance measurements etc. Every process inside industry such as pressure check, product location, fuel exhaustion, etc. should be monitored and controlled.

Khaleel et al. [79] deployed technologies of IoT in order to make efficient, interoperable and flexible car manufacturing process. Wireless sensor networks were deployed to monitor machines; identification, tracking, authorization was deployed with RFID. IoT can also be deployed in the construction industry where RFIDs can be used to track, monitor, manage manufacturing processes as well as control quality of product [80].

\section{E. Deploying IoT in providing Smart Education}

Education institutes have incorporated technology for better learning. Smart wristbands/ biometric sensors can be useful for the saving time of teachers in taking attendance. Whenever a student enters the class this wristband sends a signal to mark present. Neurosensors can be implanted to know about student's learning capabilities. IoT can also be deployed in automatically measuring the academic performance of students.

In [81] author presented a new approach where IoT can 
create a new evolution in the education system by making amendments in teaching, training and learning, experiments, schools etc. Pruet et al. [82] provided education to primary students residing in rural areas of Northern Thailand through IoT-enabled tablets.

\section{F. Smart and Safe Mining}

Mining safety is of big concern in various countries. However, IoT can be deployed to ensure safe and accident-free mining. WiFi, NFC, RFID tags deployed in mining areas has the capability of sending a warning signal. Also, mining companies in danger situations can track the location of miners and can locate or direct them accordingly. KunKun and Xiangong [83] applied IoT to detect risks and ensure safe coal mining

\section{G. Smart Agriculture}

Internet of Things occupied all fields without an exception to Agriculture. Farmers make use of this technology to modernize activities related to agriculture, weather forecasting, yielding, wildlife management water regulation [84], etc. It can be deployed to track the location of animals, disease spread out among animals and plants can be detected and controlled.

Table 5. Products Launched by Various Companies Corresponding to Application Areas Associated with Internet of Things.

\begin{tabular}{|c|c|}
\hline Applications & Products available in Market \\
\hline $\begin{array}{l}\text { SMART } \\
\text { TRANSPORT }\end{array}$ & EcoTrafix and EVlink. \\
\hline HEALTHCARE & $\begin{array}{l}\text { Nymi; Proteus Helius; Sproutling Baby } \\
\text { Monitor. }\end{array}$ \\
\hline $\begin{array}{ll}\text { SMART } & \text { HOME/ } \\
\text { BUILDING } & \end{array}$ & $\begin{array}{l}\text { Motorola 4Home; Samsung Home } \\
\text { Monitoring Kit incorporating Hub, motion } \\
\text { sensor, water leakage sensor, arrival } \\
\text { sensor; August Smart Lock. }\end{array}$ \\
\hline $\begin{array}{l}\text { SMART } \\
\text { AGRICULTURE }\end{array}$ & ThingWorx IOT platform. \\
\hline SMART GRID & $\begin{array}{l}\text { InovGrid; IssyGrid; Telegestore; GE and } \\
\text { Alstom Grid. }\end{array}$ \\
\hline $\begin{array}{l}\text { SMART } \\
\text { EDUCATION }\end{array}$ & $\begin{array}{l}\text { Samsung Magic IWB; Smart light raises } \\
\text { interactive projectors; BYOD. }\end{array}$ \\
\hline
\end{tabular}

\section{FUTURE RESEARCH TRENDS}

\section{A. Automatic Sensor Selection Based on Task (Context Awareness)}

IoT is present in everything around us; sensors are deployed in these things. Since these things are billion in number the data (big data) sensed by these sensors become difficult both for technical and non-technical users to collect and interpret and process. Perra et al. [51] identified this opportunity as Sensing-as-a-service and proposed a context-aware architecture. The challenge of collecting and processing of sensed data is of great concern in IoT and has become a new research area.

\section{B. Heading toward Green-IOT (Constructing least Energy consumption Devices)}

IoT automates the world around us. However, automating things consume a huge amount of electricity which becomes a costly process for users as well as environment. Constructing energy-efficient devices is an opportunity for IoT developers. Keeping this in context Collotta and Pau [8] incorporated BLE to make energy efficient homes. Abedin et al. [49] address issues regarding energy efficiency and proposed a G-IOT model.

\section{Constructing Social Networks for Objects}

Since IoT is a network of heterogeneous things, they must communicate with each other to provide user services. Atzori et al. [50] address a model named Social Internet of Things (SIoT) in order to depict need of communication of objects over social networks.

\section{BIG DATA IN ASSOCIATION WITH IOT}

With Big Data it is possible to extract analytics and value from data for better decision making which in turn leads to efficiency and cost or risk reduction; also it acts as a competitive advantage for businesses. Apache Hadoop, Apache Cassandra, Voldemort are some platforms for Big Data analysis. However, the data sensed by IoT is enormous to be analyzed and processed by these tools. To analyze Facebook messages received per day, Facebook used an improved version of Apache which is an integration of Apache HBase built over Hadoop [89]. Apache Spark these days is the fastest analytic tools.

The massive data gathered from IoT sensors require analysis such as pattern searching. However, existing time series data analysis services are low in efficiency and have a higher maintenance cost. To tackle this issue, $\mathrm{Xu}$ et al. [90] proposed TSAaaS for efficient and effective time series data searching. TSAaaS on evaluation was found 10 to 100 times faster than existing services and it requires only $0.4 \%$ of original data for storage.

A feasible solution for Big Data gathered from IoT is to keep an account of only quality or interesting data that will be actionable data. Pattern reductions, feature extraction, Principle Component Analysis (PCA) are suitable approaches for mining IoT data [91].

\section{CONCLUSION}

IoT is an emerging paradigm; it aims at providing quality life by connecting things around us and integration with various technologies such as Cloud Computing, Big Data, Wireless Sensor Networks, etc. IoT is considered to be highly dynamic. It automates the world around us thus providing a Smart Environment. Leveraging IoT can lead to economic growth and better sustainability. By 2025, approximately 2-3 billion people will access the internet also economic growth caused by IoT is estimated to be in the range of $\$ 2.7$ trillion to $\$ 6.2$ trillion [55].

With this context, we consider IoT as next revolution of internet. We presented an overview of IoT by describing the technologies it encompasses, emphasis on 
the application layer of a flexible layered IoT architecture We also compared the protocols of the application layer.

This paper concludes IoT to be 'Accumulate and Ubiquitous' i.e. present everywhere and anywhere. It ensues automation of our daily activities in the home, education, industry, transport, agriculture, mining, healthcare and still abundant. Despite its benefits, IoT deals with various security, energy efficiency, availability, interoperability, reliability issues, we reviewed various research papers that address these issues and provided proposals to handle them, a parametric analysis is given for the same. Future work of IoT includes gathering and processing of sensory data, having energy efficient devices, integration of IoT with cloud computing and in social networking. We also highlighted solution to handle IoT Big Data.

\section{REFERENCES}

[1] Al-Fuqaha, M. Guizani, M. Mohammadi, M. Aledhari, and M. Ayyash, "Internet of things: A survey on enabling technologies, protocols, and applications," IEEE Communications Surveys \& Tutorials, vol. 17, no. 4, pp. 2347 - 2376, jun. 2015.

[2] L. Atzori, A. Iera, and G. Morabito. "The internet of things: A survey," Computer networks, vol. 54, no. 15, pp. 2787-2805, 2010.

[3] Gubbi, R. Buyya, S. Marusic, and M. Palaniswami, "Internet of Things (IoT): A vision, architectural elements, and future directions," Future Generation Computer Systems, vol.29, no. 7, pp. 1645-1660, 2013.

[4] Borgia, "The Internet of Things vision: Key features, applications and open issues," Computer Communications vol. 54, pp.1-31, 2014.

[5] IERC Cluster SRIA, (2014). Internet of Things [Online]. Available: research.eu/about_iot.htm

[6] T. Qiu, D. Luo, F. Xia, N. Deonauth, W. Si, and A. Tolba, "A Greedy Model with Small World for Improving the Robustness of Heterogeneous Internet of Things," Computer Networks, 2016.

[7] Jiang, F. Shen, S. Chen, K. Li, and Y. Jeong, "A secure and scalable storage system for aggregate data in IoT," Future Generation Computer Systems, vol. 49, pp. 133$141,2015$.

[8] M. Collotta and G. Pau, "Bluetooth for Internet of Things: A fuzzy approach to improve power management in smart homes," Computers \& Electrical Engineering, vol. 44, pp. 137-152, 2015.

[9] F. S. Santos, H. O. Almeida, and A. Perkusich, "A personal connected health system for the Internet of Things based on the Constrained Application Protocol," Computers \& Electrical Engineering, vol. 44, pp. 122-136, 2015.

[10] Y. Xue, and R. Deters, "Resource Sharing in Mobile Cloud-computing with Coap," Procedia Computer Science, vol. 63, pp. 96-103, 2015.

[11] Y. Mao, J. Li, M. Chen, J. Liu, C. Xie, and Y. Zhan, "Fully secure fuzzy identity-based encryption for secure IoT communications," Computer Standards \& Interfaces, vol. 44, pp. 117-121, 2015.

[12] M. Marjanović, L. Skorin-Kapov, K. Pripužić, A. Antonić, and I. P. Žarko, "Energy-aware and quality-driven sensor management for green mobile crowd sensing," Journal of Network and Computer Applications, vol. 59, pp. 95-108, Jul. 2015.
[13] Betzler, C. Gomez, I. Demirkol, and J. Paradells, "CoCoAt: An advanced congestion control mechanism for CoAP," Ad Hoc Networks, vol. 33, pp. 126-139, Apr. 2015.

[14] P. Morreale, J. McAllister, S. Mishra, and T. Dowluri, "Turning Leaf: Ecovisualization for Mobile User Engagement," Procedia Computer Science, vol. 52, pp. 690-694, 2015.

[15] Á. Villalba, J. L. Pérez, D. Carrera, C. Pedrinaci, and L. Panziera, "servIoTicy and iServe: A Scalable Platform for Mining the IoT," Procedia Computer Science, vol. 52, pp. 1022-1027, 2015.

[16] Chai, J. Choi, and J. Jeong, "An Enhanced Secure Mobility Management Scheme for Building IoT Applications," Procedia Computer Science, vol. 56, pp. 586-591, 2015.

[17] He and S. Zeadally, "An Analysis of RFID Authentication Schemes for Internet of Things in Healthcare Environment Using Elliptic Curve Cryptography," IEEE Internet of Things Journal, vol. 2, no. 1, pp. 72-83, Feb 2015.

[18] N. Kumar, N. Chilamkurti, and S. Misra, "Bayesian coalition game for the internet of things: an ambient intelligence-based evaluation," IEEE Communications Magazine, vol. 53, no. 1, pp. 48-55, 2015.

[19] S. Premnath and Z. Haas, "Security and Privacy in the Internet-of-Things under Timeand-Budget-limited Adversary Model," IEEE Wireless Communications Letters, Vol. 4, No. 3, June 2015.

[20] Pan, R. Jain, S. Paul, T. Vu, A. Saifullah, and M. Sha, "A Internet of Things Framework for Smart Energy in Buildings: Designs, Prototype, and Experiments," IEEE Internet Of Things Journal, vol. 2, No. 6, December 2015.

[21] Y. F. Gomes, D. F. S. Santos, H. O. Almeida, and A. Perkusich, "Integrating MQTT and ISO/IEEE 11073 for health information sharing in the Internet of Things," in 2015 IEEE International Conference on Consumer Electronics (ICCE), 2015, pp. 200-201.

[22] S. Collier, "The Emerging Enernet: Convergence of the Smart Grid with the Internet of Things." in IEEE Rural Electric Power Conference (REPC), 2015, pp. 65-68.

[23] M. Suresh, P. S. Kumar, and T. V. P. Sundararajan, "IoT Based Airport Parking System," in IEEE Sponsored 2nd International Conference on Innovations in Information, Embedded and Communication Systems (ICIIECS), 2015, pp. 1-5.

[24] T. N. Pham, M. Tsai, D. B. Nguyen, C. Dow, and D. Deng, "A Cloud-Based Smart-Parking System Based on Internet-of-Things Technologies," IEEE Access, vol. 3, pp. 1581-1591, 2015.

[25] Kalmar, R. Vida, and M. Maliosz, "CAEsAR: A ContextAware Addressing and Routing scheme for RPL networks," in 2015 IEEE International Conference on Communications (ICC), 2015, pp. 635-641.

[26] Zhu, V. Leung, L. Shu, and E. C-H. Ngai, "Green Internet of Things for Smart World," IEEE Access, vol. 3, pp. 2151-2162, 2015.

[27] R. Zhu, X. Zhang, X. Liu, W. Shu, T. Mao, and B. Jalaian, "ERDT: Energy-Efficient Reliable Decision Transmission for Intelligent Cooperative Spectrum Sensing in Industrial IoT," IEEE Access, vol. 3, pp. 2366-2378, 2015.

[28] Y-P. Kim, S. Yoo, and C. Yoo, "DAoT: Dynamic and energy-aware authentication for smart home appliances in Internet of Things," in 2015 IEEE International Conference on Consumer Electronics (ICCE), 2015, pp. 196-197.

[29] Hussain, R. Wenbi, A. L. d. Silva, M. Nadher, and M. 
Mudhish, "Health and emergency-care platform for the elderly and disabled people in the Smart City," Journal of Systems and Software, vol. 110, pp. 253-263, Sep. 2015.

[30] D. Rosário, Z. Zhao, A. Santos, T. Braun, and E. Cerqueira, "A beaconless opportunistic routing based on a cross-layer approach for efficient video dissemination in mobile multimedia IoT applications," Computer Communications, vol. 45, pp. 21-31, Apr. 2014.

[31] M. Castro, A. J. Jara, and A. F. Skarmeta, "Enabling endto-end CoAP-based communications for the Web of Things," Journal of Network and Computer Applications, vol. 59, pp. 230-236, Oct. 2014.

[32] Luvisi and G. Lorenzini, "RFID-plants in the smart city: Applications and outlook for urban green management," Urban Forestry \& Urban Greening, vol. 13, no. 4, pp. 630-637, 2014

[33] Bekara, "Security Issues and Challenges for the IoT-based Smart Grid," Procedia Computer Science, vol. 34, pp. 532-537, 2014

[34] S. Abraham, and X. Li, "A cost-effective wireless sensor network system for indoor air quality monitoring applications," Procedia Computer Science, vol. 34, pp. $165-171,2014$.

[35] S. Elmaghraby, and M. M. Losavio, "Cyber security challenges in Smart Cities: Safety, security and privacy," Journal of advanced research, vol. 5, no. 4, pp. 491-497, 2014.

[36] M. Nitti, R. Girau, and L. Atzori, "Trustworthiness management in the social internet of things," IEEE Transactions on Knowledge and Data Engineering, vol. 26, no. 5, pp. 1253-1266, May 2014.

[37] S. Raza, H. Shafagh, K. Hewage, R. Hummen, and T. Voigt, "Lithe: Lightweight secure CoAP for the internet of things," IEEE Sensors Journal, vol. 13, no. 10, pp. 3711-3720, 2013.

[38] Huang, Y. Meng, X. Gong, Y. Liu, and Q. Duan, "A novel deployment scheme for green internet of things," IEEE Internet of Things Journal, vol. 1, no. 2, pp. 196-205, 2014.

[39] Fuhong, L. Qian, Z. Xianwei, C. Yueyun, and H. Daochao, "Cooperative differential game for model energybandwidth efficiency tradeoff in the Internet of Things," China Communications, vol. 11, no. 1, pp. 92-102, Jan 2014.

[40] Y. Zheng, S. Rajasegarar, C. Leckie, and M. Palaniswami, "Smart car parking: Temporal clustering and anomaly detection in urban car parking," in 2014 IEEE Ninth International Conference on Intelligent Sensors, Sensor Networks and Information Processing (ISSNIP), 2014, pp. 1-6.

[41] P-Y. Chen, S-M. Cheng and K-C. Chen, "Information fusion to defend intentional attack in Internet of things," IEEE Internet of Things Journal, 1, no. 4, pp. 337-348, 2014.

[42] B. Kantarci and H. T. Mouftah, "Trustworthy Sensing for Public Safety in Cloud-Centric Internet of Things," IEEE Internet of Things Journal, vol. 1, no. 4, pp. 360-368, 2014.

[43] Kiljander, A. D'Elia, F. Morandi, P. Hyttinen, J. TakaloMattila, A. Ylisaukko-Oja, J-P. Soininen, and T. S. Cinotti, "Semantic interoperability architecture for pervasive computing and Internet of Things," IEEE Access, vol. 2, pp. 856-873, 2014.

[44] C. H. Liu, J. Fan, J. W. Branch, and K. K. Leung, "Toward QoI and Energy-Efficiency in Internet-of-Things Sensory Environments," IEEE Transactions on Emerging Topics in Computing, vol. 2, no. 4, pp. 473-487, 2014.
[45] P. P. Pereira, J. Eliasson, and J. Delsing, "An authentication and access control framework for CoAPbased Internet of Things," in 2014-40 th Annual Conference of the IEEE Industrial Electronics Society, IECON, 2014, pp. 5293-5299.

[46] P. Castellani, M. Rossi, and M. Zorzi, "Back pressure congestion control for CoAP/6LoWPAN networks," Ad Hoc Networks, vol. 18, pp.71-84, 2014.

[47] R. Palattella, N. Accettura, L. A. Grieco, G. Boggia, M. Dohler, and T. Engel, "On optimal scheduling in dutycycled industrial IoT applications using IEEE802.15.4 e TSCH," IEEE Sensors Journal, vol.13, no. 10, pp.36553666, 2013.

[48] Sun, X. Zhang, and Z. Li, "The internet of things (IOT) and cloud computing $(\mathrm{CC})$ based tailings dam monitoring and pre-alarm system in mines," Safety science, vol. 50, no. 4, pp.811-815, 2012.

[49] S. F. Abedin, M. Alam, G. Rabiul, R. Haw, and C. S. Hong, "A system model for energy efficient green-IoT network," in 2015 IEEE International Conference on Information Networking (ICOIN), 2015, pp. 177-182.

[50] Atzori, A. Iera, G. Morabito, and M. Nitti, "The social internet of things (siot)-when social networks meet the internet of things: Concept, architecture and network characterization," Computer Networks, vol. 56, no. 16, pp. 3594-3608, 2012.

[51] C. Perera, A. Zaslavsky, P. Christen, and D. Georgakopoulos, "Ca4iot: Context awareness for internet of things," in 2012 IEEE International Conference on Green Computing and Communications (GreenCom), 2012, pp. 775-782.

[52] S. Fang, L. D. Xu, Y. Zhu, J. Ahati, H. Pei, J. Yan, and Z. Liu, "An integrated system for regional environmental monitoring and management based on internet of things," IEEE Transactions on Industrial Informatics, vol 10, no. 2, pp.1596-1605, 2014.

[53] R. Vargheese and Y. Viniotis, "Influencing data availability in IoT enabled cloud based e-health in a 30 day readmission context." in 2014 IEEE International Conference on Collaborative Computing: Networking, Applications and Worksharing (CollaborateCom),2014, pp. $475-480$.

[54] R. Tabish, A. M. Ghaleb, R. Hussein, F. Touati, A. B. Mnaouer, L. Khriji, and M. F. A. Rasid, "A 3G/WiFienabled 6LoWPAN-based U-healthcare system for ubiquitous real-time monitoring and data logging," in 2014 IEEE Middle East Conference on Biomedical Engineering (MECBME), 2014, pp. 277-280.

[55] J. Manyika, M. Chui, J. Bughin, R. Dobbs, P. Bisson and A. Marrs, Disruptive Technologies: Advances that Will Transform Life, Business, and the Global Economy. McKinsey Global Institute San Francisco, CA, 2013.

[56] B.Yan and G. Huang, "Application of RFID and Internet of Things in Monitoring and Anti-counterfeiting for Products," in IEEE International Seminar on Business and Information Management, ISBIM'08, 2008, vol. 1, pp. 392-395.

[57] T. Zhang, X. Wang, J. Chu, X. Liu, and P. Cui, "Automotive recycling information management based on the internet of things and RFID technology," in 2010 IEEE International Conference on Advanced Management Science (ICAMS), 2010 , vol. 2, pp. 620-622.

[58] M-C. Chung, G. M. Lee, N. Crespi, and C-C. Tseng, "RFID object tracking with IP compatibility for the internet of things," In IEEE International Conference on Green Computing and Communications (GreenCom), 2012, pp. 132-139. 
[59] Yanhui, "Internet of Things Application of RFID Technology in Warehouse Management," in Third International Conference on Instrumentation, Measurement, Computer, Communication and Control. 2013.

[60] T. Bojan, U. Kumar, and V. Bojan, "An internet of things based intelligent transportation system," in IEEE International Conference on Vehicular Electronics and Safety (ICVES),2014, pp. 174-179.

[61] P. Urien, "A secure cloud of electronic keys for NFC locks securely controlled by NFC smartphones," in IEEE 11th Consumer Communications and Networking Conference (CCNC), 2014, pp. 1120-1121.

[62] J. Park, S. Lee, S. H. Bouk, D. Kim, and Y. Hong, "6LoWPAN adaptation protocol for IPv6 packet transmission over NFC device," in 2015 Seventh International Conference on Ubiquitous and Future Networks (ICUFN),2015, pp. 541-543.

[63] C. Cervantes, D. Poplade, M. Nogueira, and A. Santos, "Detection of sinkhole attacks for supporting secure routing on 6LoWPAN for Internet of Things," in 2015 IFIP/IEEE International Symposium on Integrated Network Management (IM),2015 , pp. 606-611.

[64] T. N. Gia, N. K. Thanigaivelan, A-M. Rahmani, T. Westerlund, P. Liljeberg, and H. Tenhunen, "Customizing 6LoWPAN networks towards Internet-of-Things based ubiquitous healthcare systems," in IEEE NORCHIP, 2014, pp. 1-6.

[65] E. Boualouache, O. Nouali, S. Moussaoui, and A. Derder, "A BLE-based data collection system for IoT," in IEEE First International Conference on New Technologies of Information and Communication (NTIC),2015, pp. 1-5.

[66] Matsuoka, J. Wang, L. Jing, Y. Zhou, Y. Wu, and Z. Cheng, "Development of a control system for home appliances based on BLE technique," in 2014 IEEE International Symposium on Independent Computing (ISIC), 2014, pp. 1-5.

[67] W. Yiqi, H. Lili, H. Chengquan, G. Yan, and Z. Zhangwei, "A ZigBee-based smart home monitoring system." In 2014 IEEE Fifth International Conference on Intelligent Systems Design and Engineering Applications (ISDEA),2014, pp. 114-117.

[68] R. Chen, L. Peng, and Y. Qin, "Supermarket shopping guide system based on Internet of things." in IET International Conference on Wireless Sensor Network, 2010, pp. 17-20.

[69] M. Rathore, A. Ahmad, A. Paul and G. Jeon, "Efficient Graph-Oriented Smart Transportation Using Internet of Things Generated Big Data," 2015 11th International Conference on Signal-Image Technology \& InternetBased Systems (SITIS), Bangkok, 2015, pp. 512-519.

[70] Azzara, M. Petracca and P. Pagano, "The ICSI M2M Middleware for IoT-Based Intelligent Transportation Systems," Intelligent Transportation Systems (ITSC), 2015 IEEE 18th International Conference on, Las Palmas, 2015, pp. 155-160.

[71] R. S. H. Istepanian, A. Sungoor, A. Faisal and N. Philip, "Internet of m-health Things "m-IoT"," Assisted Living 2011, IET Seminar on, London, 2011, pp. 1-3.

[72] S. Das, M. Ballav and S. Karfa, "Application of IoT in detecting health risks due to flickering artificial lights," Advances in Computing, Communications and Informatics (ICACCI), 2015 International Conference on, Kochi, 2015, pp. 2331-2334.

[73] Y. Liu, J. Niu, L. Yang and L. Shu, "eBPlatform: An IoTbased system for NCD patients homecare in China," Global Communications Conference
(GLOBECOM), 2014 IEEE, Austin, TX, 2014, pp. 24482453.

[74] A. Al-Taee, W. Al-Nuaimy, A. Al-Ataby, Z. J. Muhsin and S. N. Abood, "Mobile health platform for diabetes management based on the Internet-of-Things," Applied Electrical Engineering and Computing Technologies (AEECT), 2015 IEEE Jordan Conference on, Amman, 2015, pp. 1-5.

[75] K. Choubey, S. Pateria, A. Saxena, Vaisakh Punnekkattu Chirayil SB, K. K. Jha and Sharana Basaiah PM, "Power efficient, bandwidth optimized and fault tolerant sensor management for IOT in Smart Home," Advance Computing Conference (IACC), 2015 IEEE International, Banglore, 2015, pp. 366-370.

[76] C. Coelho, D. Coelho and M. Wolf, "An IoT smart home architecture for long-term care of people with special needs," Internet of Things (WF-IoT), 2015 IEEE 2nd World Forum on, Milan, 2015, pp. 626-627.

[77] V. Sivaraman, H. H. Gharakheili, A. Vishwanath, R. Boreli and O. Mehani, "Network-level security and privacy control for smart-home IoT devices," Wireless and Mobile Computing, Networking and Communications (WiMob), 2015 IEEE 11th International Conference on, Abu Dhabi, 2015, pp. 163-167.

[78] W. Li, C. Pi, M. Han, C. Ran, W. Chen and P. Ke, "A scheduling method for IOT-aided packaging and printing manufacturing system," in 2015 11th International Conference on Heterogeneous Networking for Quality, Reliability, Security and Robustness (QSHINE), Taipei, 2015, pp. 335-340.

[79] Khaleel, D. Conzon, P. Kasinathan, P. Brizzi, C. Pastrone; F. Pramudianto, M. Eisenhauer, P. A. Cultrona, F. Rusina, G. Lukac, M. Paralic, "Heterogeneous Applications, Tools, and Methodologies in the Car Manufacturing Industry Through an IoT Approach," in IEEE Systems Journal, vol.PP, no.99, pp.1-1,2015.

[80] H. Min and L. Junyu, "An Intelligent System for Precast Concrete Element Manufacturing Management Based on RFID Technology," Green Computing and Communications (GreenCom), 2013 IEEE and Internet of Things (iThings/CPSCom), IEEE International Conference on and IEEE Cyber, Physical and Social Computing, Beijing, 2013, pp. 1138-1143.

[81] Zhang Tianbo, "The Internet of Things Promoting Higher Education Revolution," in 2012 Fourth International Conference on, Multimedia Information Networking and Security (MINES), Nanjing, 2012, pp. 790-793.

[82] Pruet, C. S. Ang, D. Farzin and N. Chaiwut, "Exploring the Internet of "Educational Things"(IoET) in rural underprivileged areas," 12th International Conference on Electrical Engineering/Electronics, Computer, Telecommunications and Information Technology (ECTICON), Hua Hin, 2015, pp. 1-5.

[83] Kunkun and L. Xiangong, "Reliability Evaluation of Coal Mine Internet of Things," Identification, Information and Knowledge in the Internet of Things (IIKI), 2014 International Conference on, Beijing, 2014, pp. 301-302.

[84] V. V. H. Ram, H. Vishal, S. Dhanalakshmi and P. M. Vidya, "Regulation of water in agriculture field using Internet Of Things," 2015 IEEE Technological Innovation in ICT for Agriculture and Rural Development (TIAR), Chennai, 2015, pp. 112-115.

[85] National Intelligence Council, Disruptive Civil Technologies - Six Technologies with Potential Impacts on US Interests Out to 2025 -Conference Report CR 2008-07, (2008) [Online]. Available: http://www.dni.gov/nic/NIC_home.html. 
[86] Khan, S. U. Khan, R. Zaheer and S. Khan, "Future internet: The internet of things architecture, possible applications and key challenges," in Frontiers of Information Technology (FIT), 2012 10th International Conference On, 2012, pp. 257-260.

[87] Z. Yang, Y. Peng, Y. Yue, X. Wang, Y. Yang and W. Liu, "Study and application on the architecture and key technologies for IOT," in Multimedia Technology (ICMT), 2011 International Conference On, 2011, pp. 747-751.

[88] Collina, M. Bartolucci, A. Vanelli-Coralli and G. E. Corazza, "Internet of Things application layer protocol analysis over error and delay prone links," Advanced Satellite Multimedia Systems Conference and the 13th Signal Processing for Space Communications Workshop (ASMS/SPSC), 2014 7th, Livorno, 2014, pp. 398-404.

[89] D. Borthakur, J. Gray, J. S. Sarma, K. Muthukkaruppan, N. Spiegelberg, H. Kuang, K. Ranganathan, D. Molkov, A. Menon and S. Rash, "Apache hadoop goes realtime at facebook," in Proceedings of the 2011 ACM SIGMOD International Conference on Management of Data, 2011, pp. 1071-1080.

[90] Xu, S. Huang, Y. Chen, K. Browny, I. Halilovicy and W. $\mathrm{Lu}$, "TSAaaS: Time series analytics as a service on IoT," in Web Services (ICWS), 2014 IEEE International Conference On, 2014, pp. 249-256.

[91] C. Tsai, C. Lai, M. Chiang and L. T. Yang, "Data Mining for Internet of Things: A Survey," Communications Surveys \& Tutorials, IEEE, vol. 16, pp. 77-97, 2014.

\section{Authors' Profiles}

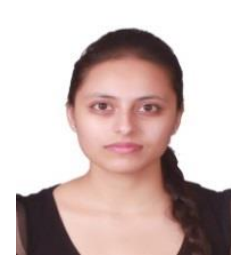

Jaideep Kaur was born in Jalandhar, Punjab, India. She completed B.Tech with Distinction from Punjab Technical University, and M.Tech from Guru Nanak Dev University, Amritsar, Punjab. Her area of research is Internet of things, Big Data.

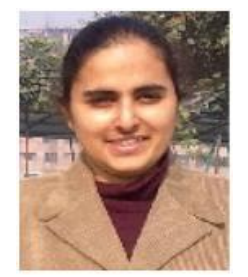

Kamaljit Kaur was born in Kapurthala, Punjab, India. She completed B.Tech. with Distinction from Punjab Technical University, and M.Tech. with Gold Medal from Guru Nanak Dev University, Amritsar. She is pursuing $\mathrm{PhD}$ in the field of Cloud Computing from Guru Nanak Dev University, Amritsar. From 2007 to 2008 she was employed with Dr. B.R.Ambedkar NIT, Jalandhar as Lecturer and from 2010 to 2012, she worked as an Assistant Professor at Lovely Professional University, Jalandhar. She joined Guru Nanak Dev University, Amritsar in July 2012 where she is currently working as an Assistant Professor. Her research interests are in Resource Provisioning in Cloud Computing, Resiliency in Cloud Computing and Distributed Systems, Big Data, IoT. Kamaljit Kaur has published and presented more than 35 papers in scientific journals and international conferences.

How to cite this paper: Jaideep Kaur, Kamaljit Kaur,"Internet of Things: A Review on Technologies, Architecture, Challenges, Applications, Future Trends", International Journal of Computer Network and Information Security(IJCNIS), Vol.9, No.4, pp. 57-70, 2017.DOI: 10.5815/ijcnis.2017.04.07 